\title{
СТРАТИГРАФИЧЕСКАЯ СХЕМА СИЛУРА ЭСТОНИИ
}

Стратиграфическое расчленение силура Эстонии рассматривалось довольно подробно в обобщающей работе «Силур Эстонии» (Кальо, 1970). Ряд причин заставляет снова вернуться к этой теме. Первая в республике завершена среднемасштабная геологическая съемка и для проведения более детальных работ необходимо соответствующее стратиграфическое основание. Вторая - на Прибалтийском стратиграфическом совещании (Вильнюс, 1976 г.) предусмотрено принять как местные, так и унифицированную региональную стратиграфические схемы. Третья - во ВСЕГЕИ разработан проект стратиграфического кодекса СССР (который будет утвержден, вероятно, в 1976 г.), позволяющий уже сейчас приступить к упорядочению номенклатуры и классификации стратиграфических подразделений по единым принципам.

Четвертой причиной и одновременно предпосылкой к ревизии и детализации стратиграфической схемы силура Эстонии является накопленный после 1970 г. новый материал как по буровым разрезам Западной Әстонии и островов (в частности, данные Э. Кала, К. Каяка, Х. Перенс по скв. Варбла, Селисте, Рухну, Каави, Тахула и др.), так и по распределению некоторых групп фауны (данные В. Вийра по конодонтам, В. Нестор по хитинозоям, Р. Мянниль по трилобитам, Т. Мярсс по телодонтам, М. Рубеля по брахиоподам, Л. Сарва по остракодам и др.). Частично эти материалы опубликованы или подготовлены к печати. Они сыграли важную роль при создании нижерассматриваемого варианта стратиграфической и корреляционной схем.

Авторы глубоко благодарны коллегам за предоставление в их распоряжение нового фактического материала и заключений.

Итоги работы нашего авторского коллектива отражены в корреляционной стратиграфической схеме (см. таблицу). Ниже рассмотрим в основном приведенные в правой части таблицы местные стратиграфические схемы двух структурно-фациальных районов. Эта часть схемы была предметом обсуждения на заседании Эстонской подкомиссии Прибалтийской региональной межведомственной стратиграфической комиссии (ПРМСК) и на пленуме последней в ноябре 1974 г. в Риге. Приводимые местные схемы приняты обоими органами в качестве рабочих. Здесь они предлагаются для более широкого обсуждения в порядке подготовки к Прибалтийскому стратиграфическому совещанию.

Местные стратиграфические схемы разработаны с учетом структурно-фациального районирования, принятого на V пленуме ПРМСК в ноябре 1973 г. в Вильнюсе. Согласно этому районированию, Прибалтийский регион делится на две структурно-фациальные зоны - Восточнои Западноприбалтийскую, которые, в свою очередь, подразделяются на районы. В пределах Әстонии в состав первой зоны входит Среднеэстонский район и в состав второй - Южноэстонский. Граница между ними и соответственно между зонами проходит примерно по линии Кауга- 


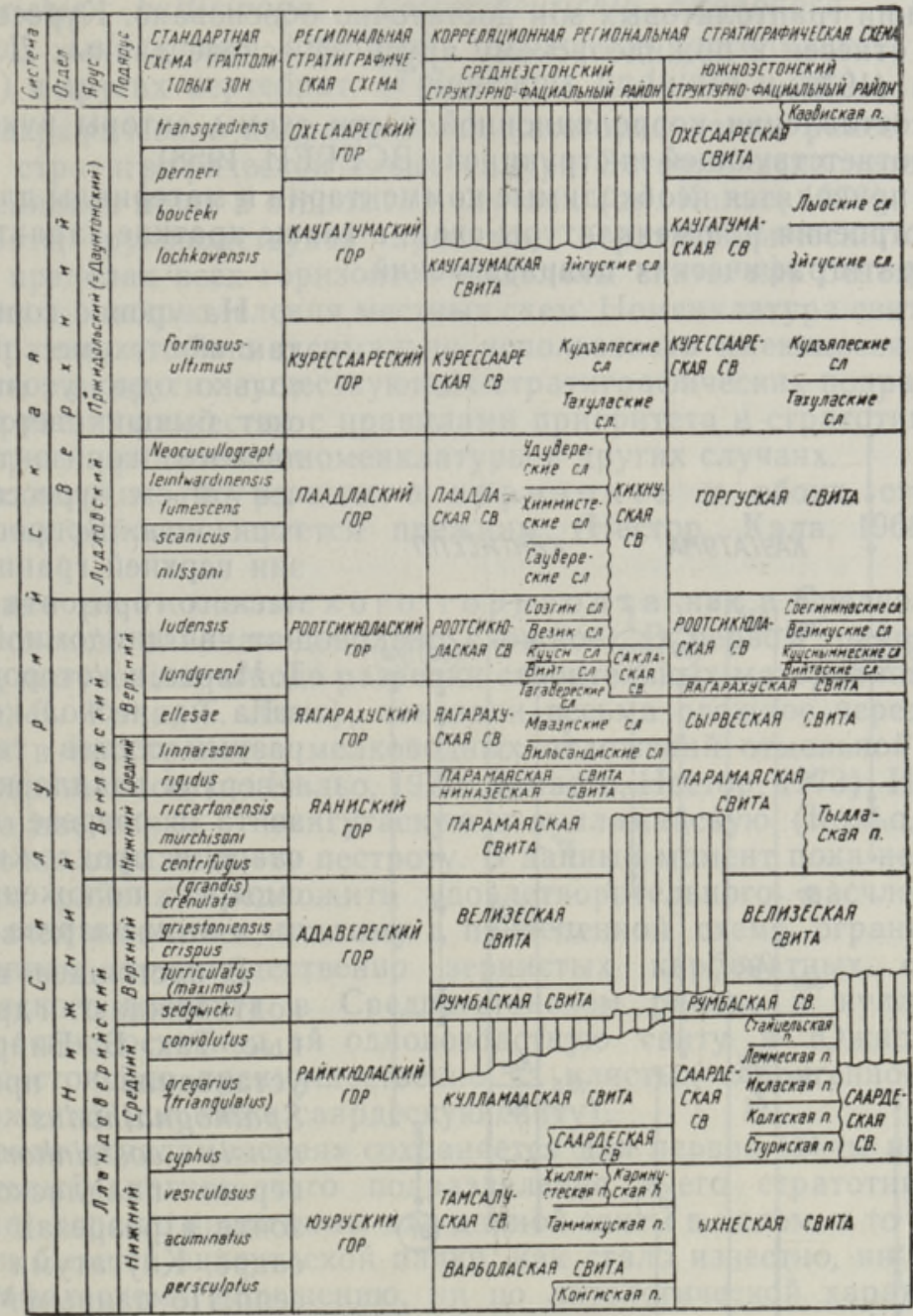

Корреляционная стратиграфическая схема силура Эстонии.

тума - южнее Пярну, севернее Абья, северо-восточнее Алуксне (Кальо, 1976). Эта граница проведена в основном по фациальному признаку, но учитывает полноту разреза и другие признаки. Однако необходимо учесть, что ввиду постоянного перемещения береговой линии бассейна на общем фоне регрессии единая для всего силура граница структурнофациальных районов для конкретных отрезков времени не совсем точна. Поэтому отдельные разрезы в пограничной полосе районов могут быть рассмотрены в составе одного или другого района. Например, кихнуская свита (см. таблицу) отнесена к Среднеэстонскому району, хотя нижнесилурийскую часть разреза Кихну следовало бы считать входящей в Южноэстонский район.

Согласно районированию, в предлагаемой таблице приведены две местные стратиграфические схемы, которые скоррелированы между собой, а также (с некоторой долей условности на уровне горизонтов) со стандартной шкалой граптолитовых зон (Корень, Кальо, 1976). Условность состоит в том, что не во всех случаях положение границ горизонтов 
в отношении граптолитовых зон достаточно обосновано. Курессаареский горизонт отнесен к пржидольскому ярусу на основе данных Д. Кальо и Л. Сарва (1976).

При составлении корреляционной части схемы авторы руководствовались соответствующей инструкцией (ВСЕГЕИ, 1958).

Ниже приводятся необходимые комментарии и материалы для обоснования построения и номенклатуры схем, а также краткие характеристики новых стратиграфических подразделений.

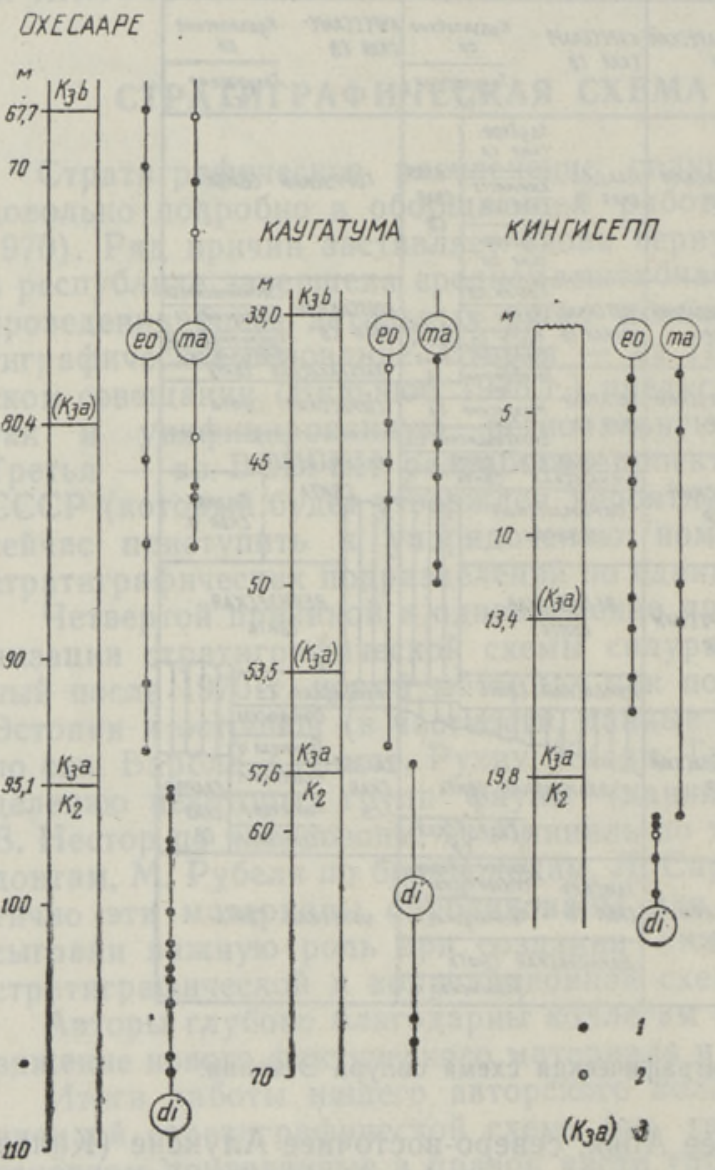

Распространение Spathognathodus steinhornensis eosteinhornensis (eo), Didymothyris didyma (di) и Delthyris magna (ma) в пограничных отложениях паадлаского и курессаареского горизонтов: 1 точное определение, 2 - определение conformis, 3 - бывшая подошва курессаареского горизонта.

На уровне горизонтов в данной схеме проведено только одно уточнение: за счет бывших верхов паадлаского горизонта увеличен объем курессаареского горизонта. Вопрос о ревизии верхней границы паадлаского горизонта был поднят в дипломной работе Т. Мярсс, в которой она ука зала на несколько своеобразный состав телодонтов в верхах паадлаского горизонта в разрезе скв. Охесааре и предложила пересмотреть положение границы в этом разрезе.

В настоящее время это подтверждают и другие данные. Так, В. Вийра (1976) установила присутствие Spathognathodus steinhornensis eosteinhornensis $\mathrm{B}$ верхах паадлаского горизонта в разрезах скв. Охесааре, Каугатума и Кингисепп. По данным М. Рубеля, там же встречается Delthyris magna, причем он появляется выше руководящего для паадлаского горизонта вида Didymothyris didyma (см. рисунок). Таким образом, явные представители т. н. пржидольской фауны появляются в верхах раннелудловского паадлаского горизонта (в ранее принятых границах) при отсутствии руководящего для этого горизонта вида. Такое фаунистическое различие считается нами достаточным для уточнения границ горизонтов и, в частности, для проведения верхней границы паадлаского горизонта по кровле удувереских слоев (в новом объеме, см. ниже) по исчезновению Didymothyris didyma и появлению в тахуласких слоях (см. определение ниже) курессаареского горизонта новых конодонтов зоны eosteinhornensis и брахиопод Delthyris magna. Кроме названных, на этом же уровне появляется новый богатый комплекс остракод 
(Navibeyrichia balticivaga, Calcaribeyrichia altonodosa, Hemsiella margaritae, Leiocyamus limpidus), телодонтов (ассоциация Thelodus sculptilis) и других вертебрат (Tolypelepis undulata и др.).

Стратиграфические подразделения категории свиты ранее использовались в стратиграфической схеме силура Эстонии непоследовательно, т. к. выделялись лишь в отдельных случаях (см. Кальо, 1970). В настоящей работе, руководствуясь проектом стратиграфического кодекса СССР, в пределах всех горизонтов выделены свиты как основные стратиграфические подразделения местных схем. Номенклатура свит выбрана таким образом, чтобы максимально использовать имеющиеся названия горизонтов или других существующих стратиграфических подразделений. Тот же принцип совместно с правилами приоритета и стратотипа соблюдался и при упорядочении номенклатуры в других случаях.

Подразделение юуруского горизонта в обоих структурнофациальных районах остается прежним (Нестор, Кала, 1968; Кальо, 1970).

Строение райккюлаского горизонта как в Средне-, так и в Южноэстонском районах довольно сложное. В первом районе новые сведения, полученные в ходе разведки строительных материалов (данные А. Хааса, Э. Кала, Т. Ланг), показали весьма сложное чередование в разрезе и в пространстве мелководных отложений отмельной и лагунной фациальных зон (по Кальо, 1970; Әйнасто, Нестор, 1973). Их деление только на две пачки - вингутаскую и кулламааскую (Кальо, 1970) недостаточно отражает эту пестроту. В данный момент пока невозможно для этого района предложить удовлетворительного расчленения на уровне пачек или слоев, поэтому в приведенной схеме ограничиваемся объединением преимущественно зернистых карбонатных отложений райккюлаского возраста в Среднеэстонском районе в кулламааскую свиту, противопоставляя ей одновозрастную свиту в Южноэстонском районе, состоящую преимущественно из илистых терригенно-карбонатных отложений (см. ниже саардескую свиту).

Название «кулламааская» сохраняется для первой свиты потому, что оригинальный диагноз этого подразделения и его стратотип (карьер Кулламаа) хорошо применимы для данной свиты в целом, в то время как стратотип бывшей вингутаской пачки, как стало известно, ни по своему стратиграфическому положению, ни по литологической характеристике не соответствует тому естественному геологическому телу (комковатым скрытокристаллическим известнякам), которое подразумевалось под этим названием.

Стратотип райккюлаского горизонта (разрез карьера Райккюла) входит в кулламааскую свиту, однако назвать свиту райккюлаской было бы неправильно, поскольку в Средней Эстонии, по исследованиям В. Нестор (1976), разрез горизонта неполный - отсутствуют в большей или меньшей мере его верхние слои.

В Южноэстонском районе распространенные по всему разрезу райккюлаского горизонта скрытокристаллические известняки большой мощности и чередующиеся с ними мергели открытошельфовой и переходной фациальных зон объеднняются в са ардескую свиту («Саарде»историческое название крайней юго-западной части Эстонии). В свите выделяются пять пачек - стуриская, колкская (Ульст, 1973) вместо применяемой ранее ремтской, иклаская, леммеская (по названию р. Лемме для «мергелевой пачки» - Кальо, Вингисаар, 1969) и стайцельская (Ульст, 1973). Последняя рассматривается в настоящей работе в объеме бывшей вингутаской пачки в разрезе скв. Икла по расчленению Д. Кальо и П. Вингисаара (1969). 
Стратотипом саардеской свиты является разрез скв. Икла в интервале $322,3-494,0 \mathrm{M}$.

В разрезе скв. Охесааре в саардеской свите пачки четко не выделяются, хотя известная ритмичность, на которой основывается расчленение свиты в стратотипическом разрезе, сохраняется. По распространению хитинозой (В. Нестор) и граптолитов (Д. Кальо) видно, что верхи горизонта выше зоны gregarius в разрезе скв. Охесааре отсутствуют.

В адавереском горизонте выделены в последнее время две свиты - известняковая и мергелевая, которые вначале считались латеральными литостратиграфическими разновидностями (Кальо, 1970), а затем залегающими друг над другом возрастными подразделениями (Әйнасто и др., 1972). В этой связи нежелательно применять для известняковой свиты одноименное с горизонтом название «адавереская», поскольку ее стратиграфический объем составляет не более половины объема адавереского горизонта в целом. Поэтому для нижней - известняковой свиты адавереского горизонта здесь предлагается название «румбаская» по названию наиболее типичной и объемистой пачки, входящей в ее состав (см. Кальо, 1970). Для верхней - мергелевой части горизонта в обоих структурно-фациальных районах сохраняется название «велизеская свита».

В я аниском горизонте в Среднеэстонском районе прежняя ниназеская пачка из-за ее сложного полифациального строения возведена в ранг свиты. Ее стратотипом является разрез клифа Ниназе на северном берегу о. Сааремаа.

Тыллаская пачка представляет собой далеко вытянутый на северовосток «язык» свнты коричневато-серых и зеленых мергелей с граптолитами (глубоководная фациальная зона), распространенной в Средней Прибалтике. Название указанной свиты вскоре будет опубликовано латвийскими коллегами.

Начиная с яагарахуского горизонта разрез силура Эстонии слагают разнообразные мелководные карбонатные отложения с более или менее ясно выраженной цикличностью. Последняя служит хорошим основанием для деления свит на слои. В объеме циклов одинакового ранга слои являются локальными, литологически неоднородными полифациальными возрастными подразделениями свит.

В Среднеэстонском структурно-фациальном районе в я агарахуском горизонте (яагарахуской свите) нижний цикл выделяется под названием «вильсандиские слон». Это в северной части о. Сааремаа биогермный комплекс, который в юго-восточном направлении замещается довольно однородными битуминозными доломитами (т. н. раугускими доломитами). В верхах цикла прослеживается выдержанный пласт глинистых микрослойчатых доломитов (включая в районе Эйкла самые древние в Эстонии эвриптеровые доломиты). По своему объему это подразделение соответствует большей части пангамягиских слоев и кесселайдской пачке прежней стратиграфической схемы (Кальо, 1970). Однако, поскольку стратотип пангамягиских слоев (обрыв Пангамяги на западе о. Сааремаа) по новейшим корреляциям оказался в вышележащих маазиских слоях (Әйнасто, 1976), необходимо для нижнего подразделения горизонта восстановить приоритет названия «вильсандиские», предложенного еще Х. Беккером (Bekker, 1925). Стратотипом вильсандиских слоев являются обнажения на западном берегу о. Вильсанди.

$M$ а азиски е слои (второй цикл) представлены сложным чередованием комковатых глинистых известняков, известковых доломитов (с множеством ходов илоедов) и коралловых известняков, для которых характерны частые поверхности перерыва. В низах прослеживается 
выдержанный пласт онколитового известняка, а в верхах - два маломощных пласта эвриптерового доломита. В объеме, предложенном Р. Эйнасто (1976), рассматриваемое подразделение соответствует верхней части пангамягиских и низам маазиских слоев в прежней их трактовке (Кальо, 1970). Стратотипом является старая каменоломня Маази на о. Сааремаа.

Верхний цикл - известняки (комковатые в нижней части разреза) с прослоями детритовых известняков (в середине цикла) и доломитов каармаского типа, а также известковых узорчатых доломитов сельгазеской пачки (в верхах цикла) - соответствует сайкласким слоям и верхам маазиских прежнего подразделения горизонта. Согласно приоритету (Аалоэ, 1960), они должны быть названы т а г в е рески м и (по каменоломне Тагавере на востоке о. Сааремаа).

Установление яагарахуского (точнее, тагавереского) возраста нижней части саклаской пачки (Эйнасто и др., 1976) заставляет возвести ее в ранг свиты под названием «саклаская». Мощность свиты в стратотипе несколько уменьшается за счет отнесения на основе цикличности ее низов с двумя выдержанными пластами эвриптерового доломита к верхам маазиских слоев. Стратотипом сакл аской свиты является интервал 48,8-71,3 $\mu$ в разрезе скв. Сакла, где он охватывает верхнюю половину тагавереских слоев яагарахуского горизонта, вийтаские и куусныммеские слои роотсикюлаского горизонта (Әйнасто и др., 1976).

В Южноэстонском районе яагарахуский горизонт в большей части сложен однообразными илисто-детритовыми комковатыми известняками (отложения открытого шельфа) сырвеской свиты, в которую А. Аалоэ (см. Кальо, 1970) включил также разнообразные детритовые и биоморфные известняки (отложения зоны отмелей) небольшой мощности (до 5 м) в верхах горизонта. С фациальной точки зрения последние правильнее отнести к яагарахуской свите, ввиду чего стратотипический объем сырвеской свиты несколько уменьшается и определяется интервалом 160,0204,9 м в разрезе скв. Охесааре. В Южноэстонском районе на основе изучения хитинозой (Нестор, 1976а) к яагарахускому горизонту отнесены верхи парамаяской свиты.

Выделенные на основе цикличности подразделения (слои) р оотси кюл аского горизонт а (см. Кальо, 1970) прослеживаются в обоих структурно-фациальных районах, составляя стратотипическую роотсикюласкую свиту («пачку» по определению Эйнасто, 1962). Лишь в восточной части распространения рассматриваемых отложений (восточная часть о. Сааремаа, п-ов Тыстамаа, о. Кихну) выше саклаской пачки (начиная с подошвы везикуских слоев) до эрозионного среза (нижней части курессаареского горизонта) распространяются однообразные микрокристаллические массивные доломиты лагунного происхождения, выделенные Р. Эйнасто и др. (1976) в кихнускую с вит у (см. таблицу). Ее стратотипом является интервал $85,8-101,4$ м в разрезе скв. Кихну.

В па адласком горизонте в его новом объеме (см. выше) по фациальным критериям выделяются три свиты: кихнуская (отложения лагунной зоны), паадлаская (преобладают отложения отмельной зоны) и торгуская (отложения открытого шельфа). Из них стратотипическая (паадлаская) свита подразделяется по цикличности на саувереские, химмистеские и удувереские слои. Первые образуют нижнюю, более нормально-морскую часть седиментационного цикла, а химмистеские слои его верхнюю, в основном лагунную часть.

Удувереские слои (первоначально выделены Э. Клааманном в ранг пачки; см. Кальо, 1970) охватывают нижнюю половину бывших когуласких слоев, тогда как верхняя половина последних включена в виде таху. 
ласких слоев в курессаареский горизонт. Они состоят из чередующихся нормально-морских известняков (на западе с биогермами катриской пачки), мергелей и лагунных домеритов. Стратотип удувереских слоев каменоломня Удувере - залегает несколько выше кровли химмистеских слоев (см. Эйнасто, 1975, рис. 3).

В Южноэстонском районе паадлаский горизонт представлен толщей комковатых илисто-детритовых известняков с частыми поверхностями перерыва и прослоями детритовых известняков и мергелей (отложения открытого шельфа), для которой здесь предлагается название «торгуская свита». Стратотип свиты - интервал $95,1-118,40$ м в разрезе скв. Oxecaape.

Для куресса ареского горизонта в данной работе предлагается двучленное деление, совпадающее в обоих структурно-фациальных районах. В нижней половине горизонта (свиты) - в тахуласких слоях преобладают известковые домериты и доломитовые мергели, внизу зеленоватые, наверху - серые. Прослоями прослеживаются обломочнодетритовые и илисто-детритовые комковатые известняки. На некоторых уровнях наблюдаются концентрации остатков рыб. Стратотип тахуласких слоев - интервал 1,5-12,3 $м$ в разрезе скв. Тахула.

Верхняя половина горизонта - кудъяпеские слои - сложена илистодетритовыми комковатыми известняками (зоны открытого шельфа) и соответствует курессаарескому горизонту в его первоначальном понимании (Кальо, 1970). Стратотипом этих слоев является разрез обнажения Кудъяпе восточнее г. Кингисеппа.

В номенклатуре стратиграфических подразделений каугату м а ского и ох е а а реского горизонтов принципиальных изменений нет. Только в последнем на восточном побережье п-ова Сырве по разрезу скв. Каави Э. Кала выделена новая каавиская пачка, сложенная домеритами и доломитами. Соответствующая часть разреза залегает стратиграфически выше известных до сих пор слоев охесаареского горизонта.

Главной целью данной работы было дать целостное представление о современной стратиграфической схеме силура Эстонии, составленной с учетом по возможности всех новых данных и на основе более или менее единых принципов. Объем статьи не позволяет нам обсудить и обосновать с помощью фактического материала все поставленные вопросы достаточно полно. Интересующихся более подробной информацией отсылаем к соответствующим публикациям (см. литературу).

\section{Л И Т Е Р А У Р А}

А ал оэ А. О. 1960. Новое в стратиграфии силура Эстонии. Тр. Ин-та геол. АН ЭССР, 5.

В и й р а В. Я. 1976. Состав и распространение конодонтов в силуре Прибалтики (скв. Oхесааре, Кункояй, Укмярге и др.). В кн.: Фацин и фауна силура Прибалтики. Таллин.

ВСЕГЕИ. 1958. Инструкция по составлению корреляционных стратиграфических схем для территории СССР и отдельных ее регнонов. М.

К а ль о Д. Л. (ред.). 1970. Силур Эстонин. Таллин.

К а льо Д. Л. 1976. Структурно-фациальное районирование снлура Прибалтики. В кн.: Фащии и фауна силура Прнбалтики. Таллин.

К альо Д., В и нг и са а р П. 1969. О разрезе райккюлаского горизонта на южной окраине Әстонии. Изв. АН ЭССР, Хим. Геол., 18, № 3.

К альо Д., Сар в Л. 1976. Расчленение верхнего силура в разрезе скв. Дубовское (Калининградская область). В кн.: Корреляция разнофациальных отложений нижнего палеозоя Прибалтики. Таллин.

Корень Т. Н., К а ль Д. Л. 1976. Граптолитовая зональная шкала силура. В кн.: Граптолиты и стратиграфия. Таллин.

Н е с т о р В. 1976. Сопоставление некоторых разрезов райккюлаского горизонта Эстонии по микропланктону. Изв. АН ЭССР, Хим. Геол., (в печати). 
Н ест ор В. В. 1976а. Зоны хитинозой яаниского горизонта (венлок Эстонии) и проблема его границ. В кн.: Корреляция разнофациальных отложений нижнего палеозоя Прибалтики. Таллин.

Н е с т ор Х. Э., К а л а Э. А. 1968. Ревизия стратиграфии низов силура Северной Прибалтики. В кн.: Стратиграфия нижнего палеозоя Прибалтики и корреляция с другими районами. Вильнюс.

Э й н а с т о Р. 1962. Сопоставление основных разрезов каармаского горизонта. Тр. Ин-та геол. АН ЭССР, 10.

Эйн а с т о Р. 1975. Стратиграфнческое положение каармаских доломитов в разрезе лудлова Эстонии. Изв. АН ЭССР, Хим. Геол., 24, № 1.

Эй н а с т О Р. 1976. Циклическое строение и стратиграфическое подразделение яагарахуской свиты в Эстонии. В кн.: Корреляция разнофациальных отложений нижнего палеозоя Прибалтики. Таллин.

Эйн а с то Р., Мя р с с Т., К ал а Э. 1976. Стратиграфическое расчленение верхневенлокско-даунтонской доломитовой толщи в разрезах Сакла, Варбла и Кихну. В кн.: Корреляция разнофациальных отложений нижнего палеозоя Прибалтики. Таллин.

Эй н а сто Р. Э., Н есто р Х. Э. 1973. Общая схема фациальной зональности Балтийского бассейна в силуре и ее палеогеографо-седиментологическая интерпретация. В кн.: Фации и геохимия карбонатных отложений. Л. - Таллин.

Э й н а с т о Р., Н е с т о р Х., К а л а Э., К а я к К. 1972. Сопоставление верхнелландоверийских разрезов в Западной Эстонии. Изв. АН ЭССР, Хим. Геол., 21, № 4.

У льс т Р. Ж. 1973. Лландоверийские отложения Северной Латвии и их корреляция. В кн.: Проблемы региональной геологии Прибалтики и Белоруссии. Рига.

B e k ke r H. 1925. Lühike ülevaade Eesti geoloogiast. (Eozoiline ja paleozoiline ladekond) Tartu.
Ннститут геологии
'Академии наук Эстонской ССР
Поступила в редакцию
$12 / \mathrm{IX} 1975$

\section{A. AALOE, D. KALJO, E. KLAAMANN, H. NESTOR, R. EINASTO}

\section{EESTI SILURI STRATIGRAAFILINE SKEEM}

Artiklis käsitletakse kahe struktuurilis-fatsiaalse rajooni (Kesk-ja Lóuna-Eestı) siluri stratigraafilist liigestust ning korrelatsiooni (vt. tabel) pärast monograafia *Eesti silur» (toim. D. Kaljo, 1970) ilmumist kogunenud uue andmestiku valgusel.

\section{A. AALOE, D. KALJO, E. KLAAMANN, H. NESTOR, R. EINASTO}

\section{STRATIGRAPHICAL CLASSIFICATION OF THE ESTONIAN SILURIAN}

The paper deals with the stratigraphical division and correlation (Tabie) of sequences of the two different structural-facial regions (Central and South Estonia) in the light of new data obtained after the publication of the monograph "The Silurian of Estonia" (Kaljo, Ed. 1970).

The revision and detailization of the stratigraphical classification is based, above all, upon the facial differences between the above-named regions, the general zonality of the basin and the cyclical structure of the sediments. Considering the standpoints of the project of the USSR stratigraphical code and simultaneously the priority principle, the corresponding local stratigraphical units (formation, members, beds) have been defined within all the stages and their nomenclature has been regulated. The units represented in the Table are as follows (in Latin script): Juuru Stage - Varbola, Tamsalu, Ohne formations, Tammiku, Koigi, Hilliste and Karinu members; Raikküla Stage - Kullamaa and Saarde formations, Sturi, Kolka, Ikla, Lemme and Staicele members; Adavere Stage - Rumba and Velise formations; Jaani Stage - Paramaja and Ninase formations, Tölla Member; Jaagarahu Stage - Jaagarahu and Sõrve formations, Vilsandi, Maasi and Tagavere beds; Rootsiküla Stage (Formation) - Viita, Vesiku, KLusnömme and Soeginina beds; Paadla Stage (Formation) - Torgu Formation, Sauvere, Himmiste and Uduvere beds; Kuressaare Stage (Formation) - Tahula and Kudjape beds; Kaugatuma Stage (Formation) - Aigu and Lōo beds; Ohesaare Stage (Formation) - Kaavi Member.

The correlation of the Estonian Silurian sequence with the unified standard of graptolite zones (Корень, Кальо, 1975) has been motivated (more accurately in the Lower Silurian) by stages and not at the level of each subdivision. 